\title{
Analytical Study of Reinforcement Consumption and Cost Management Due to Seismic Zoning
}

\author{
Rajib Kumar Das', Niloy Samadder², Gazi Md. Sharfaraz Imam Azad ${ }^{2, ~ * ~}$ \\ ${ }^{1}$ Construction Department, Walton Micro-Tech Corporation, Gazipur, Bangladesh \\ ${ }^{2}$ Deaprtment of Civil Engineering' Rajshahi University of Engineering \& Technology, Rajshahi, Bangladesh
}

\section{Email address:}

cerajib@gmail.com (R. K. Das), niloy.samadder.ns@gmail.com (N. Samadder), sharfaraz.azad.civil@gmail.com (G. M. S. I. Azad)

${ }^{*}$ Corresponding author

\section{To cite this article:}

Rajib Kumar Das, Niloy Samadder, Gazi Md. Sharfaraz Imam Azad. Analytical Study of Reinforcement Consumption and Cost Management Due to Seismic Zoning. American Journal of Civil Engineering. Vol. 4, No. 6, 2016, pp. 314-318. doi: 10.11648/j.ajce.20160406.17

Received: September 11, 2016; Accepted: September 23, 2016; Published: October 17, 2016

\begin{abstract}
This paper investigates an approach for making comparison of seismic evaluation and corresponding costs according to design of concrete frames in different seismic zones of Bangladesh. Bangladesh, one of the world's most densely populated countries with lower medium income, is vulnerable to earthquake hazards for its geological position. It is surrounded by Himalayan Arc, Shilong plateau in the north, the Burmese Arc, Arakan Yoma anticliorium in the east and complex NagaDisang-Jaflong thrust in the northeast which has made it suited to earthquake. Similarly, the Dauki Fault system along with numerous subsurface actives faults and flexure zone called Hinge Zone raises the earthquake risk factor higher. Therefore, the construction of multistoried building in the different seismic zones (Zone I, Zone II, Zone III) of Bangladesh seek several attention for making it stable to sustain the high magnitude of earthquake with economical design practice. A well known fact is that a code based high-rise construction not only safe for living but it also lessens the construction cost. In this research, it has been represented a comparative study of lateral displacement due to earthquake, construction cost and reinforcement consumption for building construction in different categories of multistoried building in the three seismic zones of Bangladesh. In the present study, earthquake load has been assigned by factorizing with specific zone factor for every zone. Finally, after conducting standard costing and estimation, it has been found that, it increases the cost of construction and amount reinforcement dramatically in the high seismic zone along with high lateral displacement as compared to the other earthquake zone.
\end{abstract}

Keywords: Earthquake, Seismic Zone, Zone Factor, Earthquake Load, Reinforcement

\section{Introduction}

Demand of land has been increased due to high growth rate of population in Bangladesh. So, there has been a noticeable increment in the number of multistoried building construction in the both categories of residential and commercial for supporting this increased amount of population. As it is not possible to expand the horizontal land then the most suitable solution for the growing demand is the construction of the multi-story structures in the available land. The research and development of high strength concrete, higher grade steel, new advanced construction technology and computer aided analysis methods have resulted a new era of all multistoried and tall buildings those are flexible, low in damping, slender and light in weight. But for the adopting the construction of multistoried buildings in the earthquake vulnerable area like Bangladesh draws attention for setting up some special prerequisite. For the modern urban development in Bangladesh, multistoried building construction is much needed in cost effective way along with the sustainable capability against high magnitude of earthquake. The acting loads on such structures spread its intensity as the story of the building increases. Similarly, high-rise building construction cost increases to resist the impact of earthquakes of high magnitude. Then, it shows significant changes in design loads, lateral displacements, construction cost according to the specific earthquake zone in case of high-rise multistoried buildings construction. Because, the loading of tall building varies from loading condition on 
low and medium rise buildings in its accumulation in to much larger structural forces. So, in the high seismic zone, the rigidity and stability of building gets affected and it becomes necessary to design the structure preferably for lateral forces, moments, story and total horizontal deflection at top most story level by adopting a cost effective way.

Earthquake is a natural phenomenon that leads to the huge devastation to the engineering systems and facilities and developed lateral load produces high stresses, produce sway movement or cause vibration. Therefore, it is very important for the structure to have sufficient strength against vertical loads with adequate stiffness to resist the impact of lateral force with minimum amount of deflection. So, most suitable way to survive through this unpredicted devastating natural disaster is by taking careful measures while planning and designing in these specified high seismic zones as well as in urban areas. So, there should have a focus on safe building design as well as in cost effectiveness.

Reddy \& Tupat discussed on the effect of zone factors on the basic of wind and earthquake loads for the higher building [1]. They also discussed about the wind loads and earthquake loads for a twelve storied RC framed. They focussed on the I-shape and cross shape structures. They initiated that wind loads are more hazardous for higher structures than the earthquake loads. Varma et al. analyzed about the seismic base shear of reinforced concrete frame structures in individual seismic zone. In these analyses the seismic base shear was determined when they used staad.pro and Etabs software package. They found that staad.pro is more reliable than Etabs for determining the seismic base shear of RC framed structures. Shakeeb et al. considered relative study on the variation of percentage of steel in different seismic zones of India [3]. According to their studies, they have been created on the seismology about $90 \%$ earthquake occurs due to tectonics. But they observed the variations of steel percentage in beams are more differentiated to columns. Kumar and Rao debated the differentiation of percentage of steel and concrete quantities of a RC structure in different seismic zones [4]. This discussion cleared on the comparison of percentage steel and concrete quantities when the building is designed for both gravity loads and earthquake forces in different seismic zones.

In this project a comparative study has been conducted on 3 building having different story level in three different earthquake zones of Bangladesh for having the clear picture of their deflection category, stability, loading conditions, construction cost and reinforcement consumption based on $\mathrm{UBC}$ and BNBC code. Computer aided analysis has been carried out by assigning earthquake zone factorized load on different structures having variety of height. Three phase of comparison is done with required analysis and estimation in the three different earthquake zone (zone I, zone II, zone III) of Bangladesh.

PHASE 1: Comparison of lateral displacement on low rise, medium rise and high rise buildings.

PHASE 2: Comparison of construction on low rise, medium rise and high rise buildings.
PHASE 3: Comparison of reinforcement consumption on low rise, medium rise and high rise buildings.

This study deals not only with the seismic evaluation as others do but it has been also concentrated on the comparative study of construction cost.

\section{Scope of the Study}

There are few investigations to be performed for the studies which are depicted below.

i. Preparation of 3D building modules assigning required loading conditions.

ii. Realization of maximum displace that could be developed while experiencing high magnitude of earthquake.

iii. Determination of various percentages to steel from zone to zone.

iv. For getting the idea of construction cost in zone of high seismicity.

v. Thus this study can be used to have preliminary idea about construction costs in different seismic zones.

\section{Analysis Methodology}

In this investigation, an approach to evaluate the variation of steel ratio and lateral displacement in different earthquake zones has been done according to UBC 1994 using a commercial software Staad.Pro v8i.

There are a number of provisions in UBC that are adopted for analyzing earthquake forces. They are:

i. Static Analysis

ii. Dynamic Analysis

Static analysis can be broadly divided into following methods:

a) Equivalent Static Force Method: In this method of analysis, a force distribution method is used. The earthquake force is applied as a static force in the required structures for analysis purpose.

b) Pushover Analysis: This method of analysis involves pushing lateral loads with an increment by following a prescribed loading pattern until the building reaches at its target displacement.

Dynamic analysis can be divided into following methods:

a) Response Spectrum Analysis: This analysis permits a multiple modes of response of a building those are to be taken into consideration. For each mode, a response is read from the design spectrum, based on the modal frequency and the modal mass, and they are then combined to provide an estimate of the total response of the structure.

b) Time History Analysis: This method of analysis can be referred to as both linear and nonlinear dynamic analysis.

In this paper, for seismic analysis equivalent static force method is adopted.

According to Bangladesh National Building Code, Bangladesh is divided into three zones based on the probable 
severe intensity of ground motion resulting from seismic waves. These zones are:

Zone I, Zone II \& Zone III. Among the three zones Zone III is most seismic prone area while zone II is moderately severe.

Three different storied buildings (six story, eight story\& ten story) are used to analyze in these three zones. The specifications of the three buildings are following

For Six Storied Building:

Table 1. Specifications of six storied building components.

\begin{tabular}{ll}
\hline Building Components & Specifications \\
\hline Beam & $300 \times 400(\mathrm{~mm})$ in cross-section \\
Column & $400 \times 400(\mathrm{~mm})$ in cross-section \\
Slab & $125 \mathrm{~mm}$ in thickness \\
Floor Height & $3000 \mathrm{~mm}$ \\
Total Height & $18 \mathrm{~m}$ \\
Bay width & $4.5 \mathrm{~m}$ \\
\hline
\end{tabular}

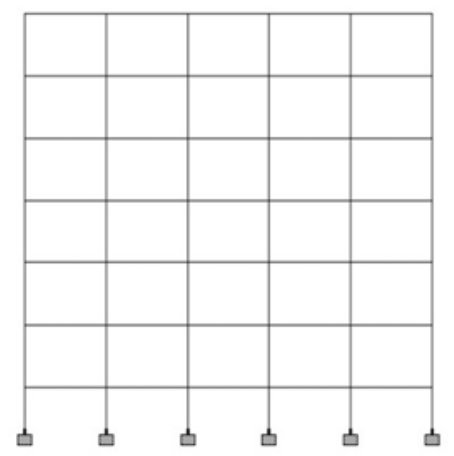

Fig. 1. Six story building.

For Eight Storied Building:

Table 2. Specifications of eight storied building components.

\begin{tabular}{ll}
\hline Building Components & Specifications \\
\hline Beam & $300 \times 400(\mathrm{~mm})$ in cross-section \\
Column & $450 \times 450(\mathrm{~mm})$ in cross-section \\
Slab & $125 \mathrm{~mm}$ in thickness \\
Floor Height & $300 \mathrm{~mm}$ \\
Total Height & $24 \mathrm{~m}$ \\
Bay width & $4.5 \mathrm{~m}$ \\
\hline
\end{tabular}

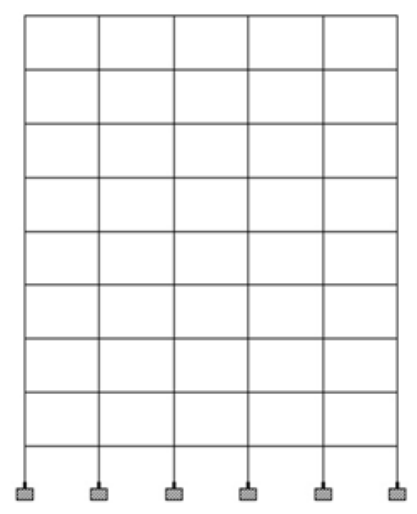

Fig. 2. Eight story building.

For Ten Storied Building:
Table 3. Specifications of ten storied building components.

\begin{tabular}{ll}
\hline Building Components & Specifications \\
\hline Beam & $300 \times 400(\mathrm{~mm})$ in cross-section \\
Column & $500 \times 500(\mathrm{~mm})$ in cross-section \\
Slab & $125 \mathrm{~mm}$ in thickness \\
Floor Height & $300 \mathrm{~mm}$ \\
Total Height & $24 \mathrm{~m}$ \\
Bay width & $4.5 \mathrm{~m}$ \\
\hline
\end{tabular}

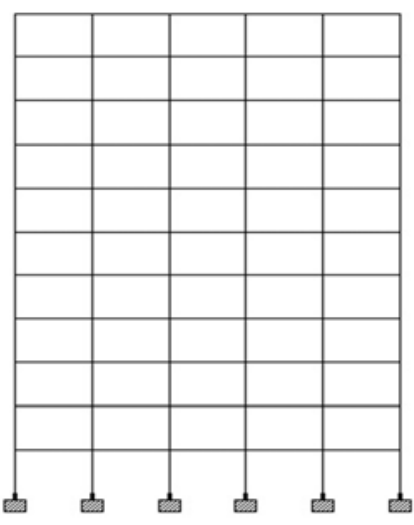

Fig. 3. Ten story building.

Dead load includes mass of all building components and live loads are taken from UBC 1994. As staad.pro seismic load generator follows some certain codes, for that purpose here UBC94 code procedure has been adopted. The values of base shear as per BNBC2006 and UBC94 are almost same. Total load calculations have been done according to UBC 94.According to UBC 94 following equations have been used: Design base shear

$$
\begin{aligned}
& V=\frac{Z I C}{R w} W \\
& \mathrm{C}=\frac{1.25 S}{T^{\frac{2}{3}}} \\
& T=C t(h n)^{\frac{3}{4}}
\end{aligned}
$$

$\mathrm{I}=$ Structural Importance

$\mathrm{T}=$ Structural period

$\mathrm{Ct}=0.073$ (For Concrete structures)

$\mathrm{hn}=$ Building height

$\mathrm{S}=$ Site coefficient $=1.5$

Rw is a numerical coefficient represents the inherent over strength and global ductility capacity of lateral force resisting system

$\mathrm{W}$ is the seismic mass.

Table 4. Table of Zone coefficients as per BNBC2006.

\begin{tabular}{ll}
\hline Zone & Coefficient \\
\hline I & 0.075 \\
II & 0.15 \\
III & 0.25 \\
\hline
\end{tabular}

\section{Results}

The main focus of present study deals with the different 
lateral displacements, costs of buildings in different seismic zones and required reinforcements percentage in distinct seismic zones.

Here, the graphical representation of the multistoried building with respect to lateral displacement has been presented in figure 5. Horizontal axis indicates the story while vertical axis indicates the lateral displacements in $\mathrm{mm}$. The lateral displacement increases with the increase of the story. The differences among the models have been illustrated by the effect of zone coefficient. We can perceive that the lateral displacement changes gradually between the zone I and zone II. But here in zone 3 shows a noticeable increase which is really a remarkable change. For construction in zone III, we should analyze the buildings with more care following the regulations of corresponding building code of that zone. Because we already observed that the lateral displacement is abruptly change in zone III. The chart also give the idea that zone factor has the higher affects on higher storied buildings. The differences of displacements in different zones are higher in 10 storied building. It gives the output that buildings with more height are more susceptible to earthquake damage.

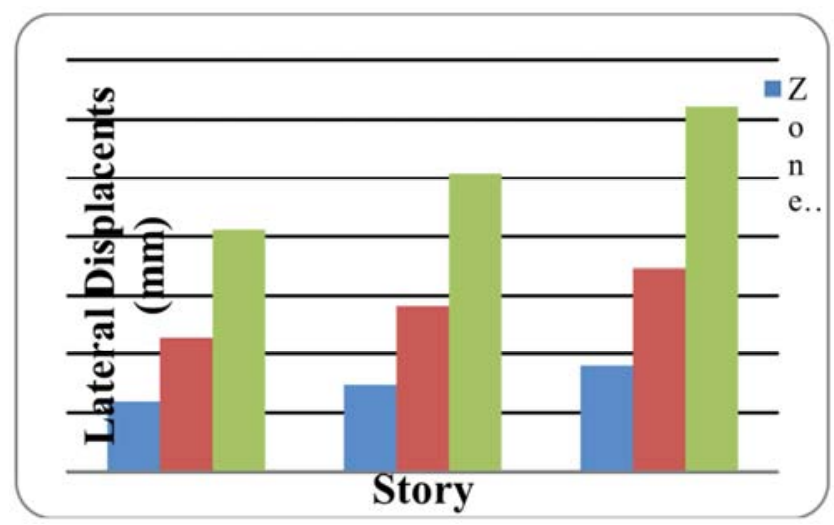

Fig. 4. Chart for Lateral displacements with respect to Story levels.

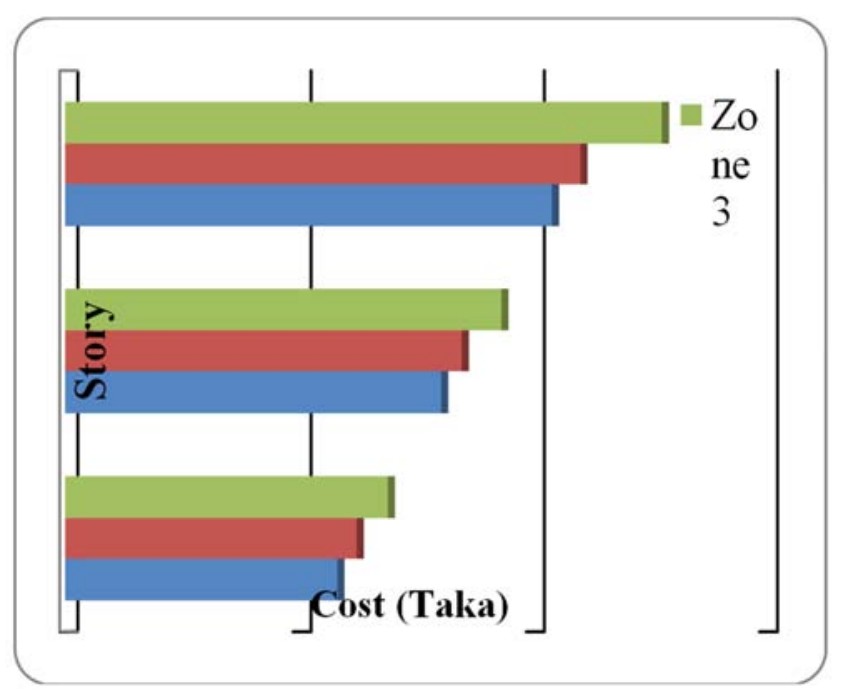

Fig. 5. Chart for costs with the variation of story level.

The relationship between the costs of each model shown in figure 5 as we told before that each samples shows different phenomenon in different stage. The instruction of the number of story is exhibited in vertical axis and the cost of the story is exhibited in horizontal axis. As we all know that the cost is escalated with the escalating of the story. But this escalating is also caused by different kinds of reason. For constructing a multistoried building, we must preserve a few codes like UBC \& BNBC. In figure 2, we can perceive that the cost quantity of zone III is rapidly changing with the respect of zone I and zone II. The effect of zone factor is also reflected in the cost quantity which shows that higher story buildings will face more construction cost.

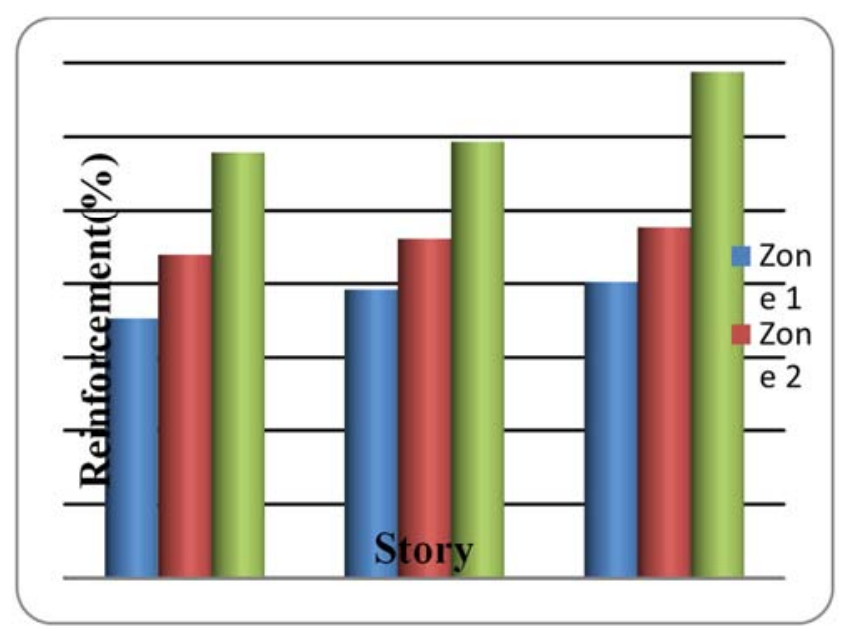

Fig. 6. Chart for Reinforcement ratio with respect to story level.

The relationship between the story and the percentage of the reinforcement is shown in figure 6 . The specification of the percentage of the reinforcement is arranged in vertical axis and the number of story is arranged in horizontal axis. We previously told that each zone shows the different types of changes. In figure 3 , we notice that the percentage of the reinforcement increases with the change of the number of story. If we notice the changes of zones, we can observe clearly the radical change of zone 3 .

\section{Conclusions}

The main focus of present study deals with the different lateral displacements, costs of buildings in different seismic zones and required reinforcements percentage in distinct seismic zones.

From the analyses and discussions above, a number of assumptions can be found out.

a. Seismic zone coefficients are liable for the increasing amount of cost of reinforcement.

b. The increasing of reinforcement percentage get higher with the increments of building height.

c. Increasing pattern of lateral displacements is controlled by height of story. 


\section{References}

[1] Reddy K. R. C. and Tupat S. A.(2014), "The effect of zone factors on wind and earthquake loads of highrise structures", IOSR Journal of Mechanical and Civil Engineering (IOSRJMCE) e-ISSN: 2278-1684, p-ISSN: 2320-334XPP 53-58.

[2] Varma S., Malar A., Thenmozhi S., Suriya T., Murali G., Venugopal B. and Karthikeyan K., "Comparative Study of Seismic Base Shear of Reinforced Concrete Framed Structures in Different Seismic Zone", THE INTERNATIONAL JOURNAL OFSCIENCE \& TECHNOLEDGE (2014), Vol 2, issue $8, \mathrm{Pp}$ 74-77.

[3] Shakeeb S. S. M., Bhushan B. S., Maneeth P. D. and Adulla S. "Comparative Study on Percentage Variation of Steel In Different Seismic Zones Of India", International Research Journal of Engineering and Technology (IRJET), p-ISSN: 2395-0072, e-ISSN: 2395-0056Volume: 02 Issue: 07 | Oct2015.

[4] Kumar K. and Rao G. P., "COMPARISON OF PERCENTAGE STEEL AND CONCRETE QUANTITIES OF A R. C BUILDING IN DIFFERENT SEISMIC ZONES”,

IJRET: International Journal of Research in Engineering and TechnologyeISSN: 2319-1163 | pISSN: 2321-7308, Volume: 02 Issue: 07 | Jul-2013.

[5] Sazzad M. M. and Azad M. S. "Effect of building shape on the response to wind and earthquake", International Journal ofAdvanced Structures and Geotechnical Engineering ISSN 2319-5347, Vol. 04, No. 04, October 2015.

[6] Sultana S., Rahman U. and Saika U., "EARTHQUAKE, CAUSE SUSCEPTIBILITY AND RISK MITIGATION IN BANGLADESH", ARPN Journal of Earth Sciences, VOL. 2, NO. 2, JUNE 2013, Pp 70-80

[7] Shah H. J. and Jain S. K., "Design Example of a Six Storey Building", Document No.: IITK-GSDMA-EQ26-V3.0, Final Report: A - Earthquake Codes, IITK-GSDMA Project on Building Codes.

[8] Jain S. K., "Explanatory Examples on Indian Seismic".

[9] Code IS 1893 (Part I), Document No.: IITK-GSDMA-EQ21V2.0, Final Report: A - Earthquake Codes, IITK-GSDMA Project on Building Codes. Uniform Building Code 1994.

[10] Bangladesh National Building Code 2006. 